\title{
A elaboração de resumos documentários como atividade do tratamento temático da informação na prática profissional bibliotecária
}

\author{
Lais Pereira de Oliveira \\ Doutoranda; Universidade Estadual Paulista, Marília, SP, Brasil; \\ laispereira2@yahoo.com.br \\ Daniel Martínez-Ávila \\ Doutor; Universidade Estadual Paulista, Marília, SP, Brasil; \\ martinez.avila@unesp.br \\ José Augusto Chaves Guimarães \\ Doutor; Universidade Estadual Paulista, Marília, SP, Brasil; \\ chaves.guimaraes@unesp.br
}

\begin{abstract}
Resumo: Considerando o resumo documentário enquanto elemento inerente ao tratamento temático da informação, analisa-se em que medida é elaborado durante o processamento técnico nas bibliotecas, como forma de apoiar a indexação para garantir uma representação temática completa dos materiais. Valendo-se de coleta dos dados mediante questionário com perguntas fechadas, aplicado via Google Formulários a 30 bibliotecários goianos em atuação em diferentes tipos de unidades de informação, procede-se a uma sistematização estatística. Os resultados indicam que a elaboração de resumos documentários não é uma prática comumente conduzida pelos bibliotecários, em detrimento da classificação e da indexação. O resumo está presente em apenas $16,7 \%$ das unidades de informação, apesar de enxergado em sua relevância por 96,7\% dos respondentes. Evidenciam-se, ainda, dificuldades de diversas ordens para sua elaboração. Conclui-se que o resumo, apesar de reconhecido pelos profissionais investigados em sua importância, não está sendo aproveitado nas unidades de informação como parte do tratamento temático da informação como, de fato, deveria acontecer.
\end{abstract}

Palavras-chave: Tratamento temático da informação. Resumo documentário. Elaboração de resumos.

\section{Introdução}

A elaboração de resumos documentários é parte importante do tratamento temático da informação, uma vez que viabiliza a constituição de texto conciso e direto sobre um documento, destacando aspectos que melhor o caracterizem em termos do assunto ou assuntos tratados. Desse modo, o resumo - fruto de uma 
operação de tratamento textual - representa um complemento direto à indexação, relacionando-se intimamente com esta (KOBASHI, 1997; LANCASTER, 2004).

O resumo é também um instrumento de grande relevância para a comunidade científica e acadêmica (SIMÕES, 2015), sinalizando sobre o teor das produções científicas e auxiliando significativamente a pesquisa, uma vez que permite maior precisão à busca informacional. Segundo aponta Jizba (1997, p. 36, tradução nossa) "resumos ou notas de resumos são de valor significativo para quem procura informação" e poderiam ser de muita utilidade para a descrição de recursos caso fossem consistentemente aplicados junto a catalogação e metadados.

O presente artigo se dedica, portanto, ao tratamento temático da informação, com foco nas ações analíticas e representativas para a elaboração de resumos documentários, buscando avançar nas compreensões acerca do tratamento biblioteconômico nesse âmbito. Tem por premissa o binômio estabelecido entre o índice de assuntos e o resumo, como produtos de organização da informação mutuamente complementares.

Desse modo, a investigação se insere em torno da problemática de quais usos têm sido feitos do resumo, no amplo aspecto do tratamento temático da informação. Inclusive porque pouco tem sido discutido sobre resumo documentário, isoladamente, seja como instrumento de representação seja como elemento de difusão científica (OLIVEIRA, 2018). Muito associado à indexação, o resumo acaba perdendo espaço no aporte teórico em Biblioteconomia, assim como no âmbito prático dessa área, presente nas unidades de informação.

Centralmente, a investigação norteia-se pelo objetivo de analisar em que medida o resumo documentário é elaborado durante o processamento técnico nas bibliotecas, como forma de apoiar a indexação para garantir uma representação temática completa dos materiais. Parte-se da hipótese que, apesar da sua relevância, o resumo ainda é pouco explorado pelos bibliotecários no desempenho de suas funções de tratamento da informação. 
Espera-se, com o estudo, contribuir para o universo teórico ao se explorar uma dimensão distinta da tão discutida indexação de assunto, representada pelos resumos documentários. Em termos práticos, lança discussões que podem evidenciar para o contexto investigado a importância de se atentar para a elaboração do resumo documentário, em vias de aproveitar todo o potencial representativo de tal instrumento no processamento técnico cotidianamente desenvolvido nas unidades de informação.

\section{Resumo documentário}

O resumo é um novo texto constituído para representar um original, de modo breve e direto. De acordo com Lunardelli (2017, p. 5) o resumo "institui-se como o recurso de descrição do conteúdo temático de objetos informacionais que mais se aproxima do texto original". Não se caracteriza, portanto, como um extrato do material resumido. A este respeito, Lancaster (2004, p. 100) explica que:

É preciso distinguir entre as palavras resumo e extrato. Este é uma versão abreviada de um documento, feita mediante a extração de frases do próprio documento [...]. O verdadeiro resumo, ainda que inclua palavras que ocorram no documento, é um texto criado pelo resumidor e não uma transcrição direta do texto do autor.

O resumo pode, ainda, ser caracterizado como um dos processos de sumarização da informação, assim como a indexação, a catalogação de assunto e a classificação, os quais possibilitarão a recuperação da informação (FUJITA; RUBI; BOCCATO, 2009). Pode-se dizer que "a elaboração de resumos é o terceiro processo de descrição de conteúdo da organização da informação. Sua função é complementar a informação dada pela classificação e pela indexação" (CAFÉ; SALES, 2010, p. 119).

Cintra et. al. (1994) localizam o resumo dentro do escopo da síntese e da representação documentárias. Segundo as autoras, advindas do processo de análise essas atividades podem apresentar-se sob duas formas: "o resumo, que é feito sem a intermediação de uma linguagem documentária e o índice, que para maior qualidade, deve ser elaborado a partir de uma LD determinada" (CINTRA et. al., 1994, p. 28), ou seja, uma linguagem documentária. Assim, o resumo se 
torna menos dependente de uma linguagem documentária para sua consecução, obedecendo mais à linguagem natural.

De acordo com Lancaster (2004) tanto os próprios autores, enquanto especialistas no assunto, como os resumidores profissionais, podem elaborar resumos. Na sua elaboração devem ser destacados elementos representativos do assunto, sem dispersão, detalhes e exemplos. Estes poderão ser consultados no texto resumido, caso o leitor decida por sua utilização. Logo, a elaboração de um resumo "supõe a compreensão de textos e a seleção de informações com base na hierarquização" (KOBASHI, 1997, p. 205). O propósito de elencar elementos de modo substancial é, então, o foco da ação. Pode-se afirmar ainda que enquanto:

Produto da síntese realizada, sua elaboração é resultado de processo cognitivo de relativa complexidade, o qual consiste em identificar a informação mais relevante e reapresentá-la o mais fidedignamente possível. Trata-se de uma reunião das ideias, premissas e fatos principais apresentados no texto original. (LUNARDELLI, 2017, p. 6).

Em razão dessa dimensão cognitiva complexa, a elaboração do resumo reveste-se de profundidade, minúcia e certa dificuldade, o que pode ser determinante para abdicação de sua elaboração no processo técnico realizado em bibliotecas. Justamente nesse cerne que se afigura a presente pesquisa. Até porque é importante a exploração do assunto para sua cobertura e amplitude teórica e, ainda, como forma de propor soluções para a prática profissional em torno dele.

Uma vez constituído como parte das ações biblioteconômicas de análise e síntese, o resumo assume ares de instrumento documentário, sendo fundamental por ocasião de seleção da informação, uma vez que permite que o leitor decida se o item pode ou não satisfazer seu interesse (LANCASTER, 2004). Especificamente no âmbito dos sistemas de recuperação da informação, os resumos "facilitam a identificação de itens pertinentes e proporcionam acesso a itens armazenados" (Ibid., p. 105), aspectos estes que reiteram sua importância para o usuário da informação, no conhecimento temático dos materiais dispostos em bibliotecas. 
Importante destacar a proximidade entre resumo e indexação, uma vez que o primeiro permite representar assunto mediante constituição textual condensada, enquanto a segunda viabiliza a representação temática pelo emprego de termos indicativos do conteúdo. Com isso, e considerando que ambos permeiam-se por uma análise conceitual, observa-se que o processo de condensação para elaboração "ajuda na decisão sobre o que deve ser incluído e o que pode ser omitido na indexação" (LANCASTER, 2004, p. 123).

Desse modo, cabe ao bibliotecário dedicar igual atenção a ambos os processos - condensação e indexação - com a mesma complementaridade que ocorre entre a catalogação e a classificação. Indexar e resumir precisam estar no cerne do processamento técnico, ainda que isso exija mais capacitação e preparo do profissional, pois o tratamento temático de uma obra vai muito além de sua representação por meio de um conjunto de descritores. Trata-se de caracterizar e sintetizar instâncias de conteúdo que apenas os termos de indexação isolados, não podem evidenciar. É preciso contemplar uma dimensão textual e, portanto, mais facilmente inteligível por possuir sintaxe, coesão e coerência textual.

Nesse sentido - novamente destacando a estruturação - o resumo precisa trazer o teor do documento, constituindo uma representação mais ampla que os termos de indexação, uma vez que se efetiva no formato textual. Para tal, selecionam-se "as informações consideradas essenciais, tendo em vista a produção de um novo texto condensado, para um interlocutor determinado" (KOBASHI, 1997, p. 201). Desse modo, o conceito de "informação essencial" se amplia, uma vez que atinge não apenas aquela que se apresenta com maior relevância ao documento como também outras que, ainda que secundárias, possam ir ao encontro de necessidades específicas da comunidade usuária por conta de seu ineditismo, por exemplo.

Por constituir uma apresentação concisa de um original (ASSOCIAÇÃO BRASILEIRA DE NORMAS TÉCNICAS, 2003), o resumo pressupõe, em sua elaboração, uma efetiva capacidade de síntese. Essa síntese, por sua vez, deve "respeitar a ordem, a estrutura, o sentido estabelecido pelo autor" (LUNARDELLI, 2017, p. 6), evitando-se a interferência do resumidor a partir de juízos de valor. 
Aliás, "em que pesem as distinções conceituais de resumo na área de Ciência da Informação, ele está necessariamente ligado à ideia de síntese ou concisão, ao que se alia a fidedignidade de representação do conteúdo do documento (precisão)" (GUIMARÃES, 2005, p. 4). Ater-se ao que é realmente elemento-chave para a composição do resumo é, portanto, fundamental.

Vale destacar que a síntese, na elaboração do resumo, vai muito além do mero privilegiamento de alguns conteúdos em detrimento de outros, pois pressupõe um processo de seleção e de hierarquização de modo a eliminar redundâncias e garantir a representatividade de informações essenciais à compreensão temática do texto, em detrimento de aspectos auxiliares que evidenciariam uma informação meramente acessória (KOBASHI, 1997; LANCASTER, 2004). Com isso, tem-se aquilo que Terra (2017, p. 60) denomina "equivalência informativa" entre o resumo e o texto original, garantindo a efetivação desse vínculo por meio de uma "economia de meios e a adaptação a uma nova situação de comunicação".

O problema está no fato de muitos resumos serem elaborados sem preocupação estrutural (GUIMARÃES; SANTOS, 2016). Entretanto, a condensação da informação deve se subordinar a determinadas regras (LUZ, 1996). Nesse ponto, a normalização do resumo também deve ser considerada, assim como diretrizes para construção do mesmo, sobretudo por sua importância no contexto documentário (GUIMARÃES, 2005).

Enquanto características de um bom resumo tem-se justamente: brevidade, exatidão e clareza (LANCASTER, 2004). Sua estrutura deve ser unificada e desenvolvida de forma lógica (LUZ, 1996). A este respeito, Terra (2017, p. 60) evidencia que:

No resumo, as operações de eliminação dos dados supérfluos, de substituição de um conjunto de elementos ou de ações por um termo genérico, capaz de englobamento, bem como a macroseleção e a invenção, escolhendo a frase que ilustra a ideia principal ou criando uma caso não exista, constituem operações estruturantes.

Isso porque o resumo "muitas vezes se perde em informações supérfluas e deixa de lado aspectos fundamentais do conteúdo do texto a ser resumido. 
Outras vezes, o texto peca por falta de clareza, precisão ou mesmo concisão" (GUIMARÃES; SANTOS, 2016, p. 33).

Guimarães (2005, p. 5), por sua vez, lembra que:

O resumo não pode conter pontos obscuros, contradições (que porventura gerem interpretações dúbias) ou ainda vocabulário não condizente com o público a que se destina, pois não se pode esquecer que ele deve ser um documento por si só, cujo entendimento independe da leitura do documento original (resumo que requer do pesquisador a leitura do documento original para sanar dúvidas ou obscuridades não é, em verdade, um resumo).

Além disso, concisão, precisão e clareza são as qualidades mais importantes no resumo (LUZ, 1996). O atendimento a certos critérios auxilia, desse modo, no cumprimento do próprio papel do resumo. Sendo que "no universo científico o resumo deve garantir a expressão do tema ou natureza do trabalho, da metodologia, dos objetivos, dos resultados obtidos e das conclusões que daí decorrem, apresentando essas ideias de forma lógica" (GUIMARÃES; SANTOS, 2016, p. 33-34).

Ainda assim, dificuldades existem ao elaborar um resumo, seja em função dos distintos formatos e suportes da informação ou mesmo, das diferentes composições textuais. Pode-se afirmar que "a heterogeneidade dos resumos documentários utilizados nos sistemas informacionais reflete a precariedade dos padrões utilizados em sua elaboração" (KOBASHI, 1997, p. 202). E deve-se lembrar também, que o texto não é a única tipologia presente nas unidades de informação, a se considerar a imagem e o som presentes em materiais de outra ordem, tornando o desafio do bibliotecário resumidor ainda maior.

\section{Metodologia}

A pesquisa caracteriza-se como exploratório-descritiva de natureza quantitativa. Isso porque deteve-se à investigação de uma temática escassamente trabalhada em separado da indexação: o resumo documentário. Este foi então analisado e descrito à luz de dados estatisticamente compostos, buscando-se ampliar sua compreensão. Nesse ponto, o foco recaiu sobre a quantificação. 
A população de pesquisa contemplou bibliotecários brasileiros ${ }^{1}$ em atuação nas mais diversas categorias de unidades de informação: escolares, especiais, especializadas, públicas e universitárias. O universo investigativo, contudo, priorizou profissionais alocados no Estado de Goiás no desempenho da função e, devidamente registrados no Conselho Regional de Biblioteconomia $1^{\text {a }}$ Região (CRB-1).

A classe bibliotecária de Goiás foi selecionada por simples conveniência para o acompanhamento e conferência de resultados, sendo que as características dos profissionais do Estado de Goiás não impedem que os dados sejam generalizados a outros contextos brasileiros. Trata-se pois, de um universo que enseja - dentre outras - atividades detidas ao tratamento da informação, como acontece nas demais instâncias informacionais brasileiras. Isso sem falar na própria natureza do escopo escolhido para a pesquisa, presente em outros estados do país e, com manifestações muito próximas das que se estabelecem nas bibliotecas goianas em termos de processo técnico.

De um universo de 356 bibliotecários com registro profissional ativo em Goiás, estabeleceu-se uma amostragem de 10\% sobre esse conjunto, ou seja, 35 pessoas. A base para delimitação da amostra foi o conjunto estatístico obtido junto ao Conselho Regional de Biblioteconomia no mês de julho de 2018, que apresenta o número de profissionais registrados e em atividade.

Portanto, a partir do dado numérico do CRB-1 buscou-se selecionar amostragem diversificada de 35 profissionais, de modo distribuído, equilibrado e equitativo. Esta contemplou, então, bibliotecários goianos de centros de documentação e bibliotecas escolares, especiais, especializadas, públicas e universitárias.

A amostra utilizada foi de tipo estratificada, uma vez que se priorizou a obtenção de estratos de respostas de profissionais atuantes em diferentes tipos de unidades. Assim sendo, buscou-se contemplar bibliotecários de instâncias distintas, de modo a enxergar a prática de resumir nessa diversidade de âmbitos.

A essa parcela amostral - considerando-se a distribuição pelos distintos tipos de unidade de informação - foi encaminhado o instrumento e explicada a natureza da investigação. Obteve-se retorno de 30 respondentes no período 
estipulado para retorno, que foi de 30 dias. Subsequentes contatos não retornaram um número maior de respostas das iniciais.

A coleta dos dados foi realizada mediante aplicação da técnica de questionário, consubstanciado em formulário online com doze perguntas fechadas, duas das quais permitiam marcar mais de uma alternativa e o restante, de múltipla escolha. Os dados foram analisados a partir da sistematização estatística pela constituição de gráficos.

\section{Análise e interpretação dos dados}

A pesquisa tencionou investigar a elaboração de resumos documentários no âmbito do processamento técnico desenvolvido pelos bibliotecários nas unidades de informação. Para tanto, o primeiro bloco do questionário reuniu dados de caracterização do profissional e da unidade em que atua, como forma de melhor compreender o contexto investigado. A pergunta inicial indagou os participantes sobre sua faixa etária. O gráfico abaixo expõe os percentuais:

\section{Gráfico 1 - Faixa etária.}
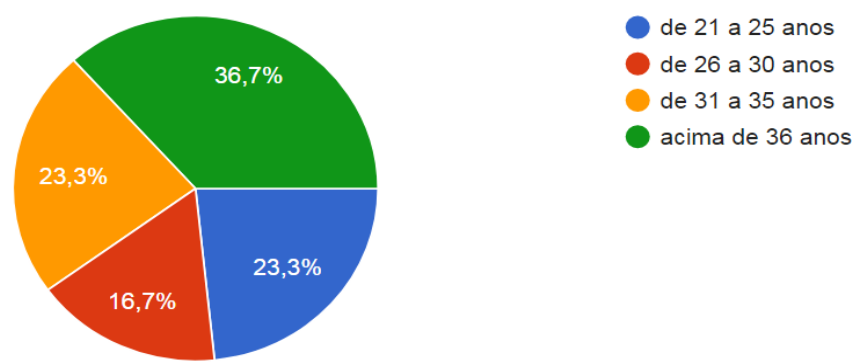

Fonte: elaborado pelos autores (2019).

Como demonstrado no gráfico, de um conjunto de 30 bibliotecários, 11 deles $(36,7 \%)$ têm acima de 36 anos e sete $(23,3 \%)$, têm entre 31 e 35 anos de idade. Há ainda sete $(23,3 \%)$ na faixa de 21 a 25 anos e cinco (16,7\%), na de 26 a 30 anos. São, portanto, profissionais com mais vivência, a maior parte acima dos 30 anos.

Apesar disto, conclusões tecidas unicamente a partir da faixa etária podem se tornar reducionistas. Mesmo porque há alunos que ingressam no curso de Biblioteconomia após terem cursado outra graduação ou depois de um 

do tratamento temático da informação na prática profissional bibliotecária

Lais Pereira de Oliveira, Daniel Martínez-Ávila e José Augusto Chaves Guimarães

período afastados dos estudos. Em função disto a caracterização envolveu outros questionamentos complementares.

Assim, a questão seguinte questionou cada profissional sobre o tempo que havia concluído a graduação em Biblioteconomia, em condições de fazer uma correlação e amparar os comentários possíveis à primeira vista diante dos resultados da questão inicial. O gráfico a seguir apresenta os resultados:

Gráfico 2 - Tempo que concluiu a graduação em Biblioteconomia.

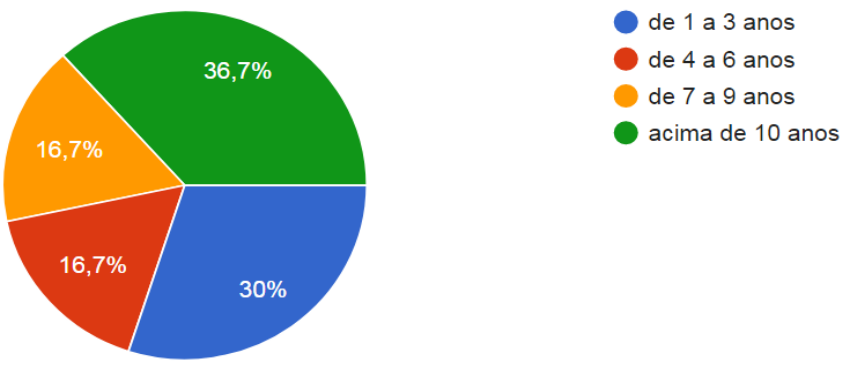

Fonte: elaborado pelos autores (2019).

Nota-se pelos percentuais acima que os bibliotecários têm, em sua maioria, um tempo razoável de formados. Um quantitativo de 11 profissionais (36,7\%) se formou há mais de dez anos; cinco $(16,7 \%)$ têm entre sete e nove anos de formados e outros cinco $(16,7 \%)$, entre quatro e seis anos. Esse conjunto representa, sozinho, $70 \%$ dos respondentes. Depreende-se então que se trata, de fato, de um grupo de sujeitos com relevante bagagem, adquirida ao longo de um considerável período de conclusão da graduação.

Em complemento à questão exposta acima, os bibliotecários também foram indagados acerca do tempo de experiência na profissão. O gráfico abaixo demonstra os percentuais:

Gráfico 3 - Tempo de experiência como bibliotecário.
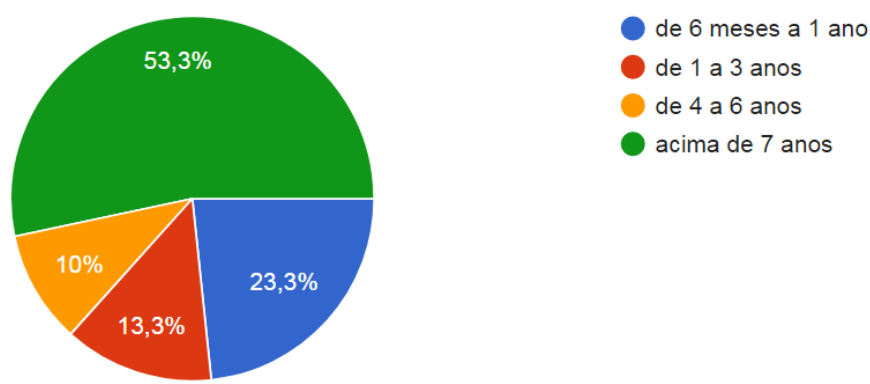

Fonte: elaborado pelos autores (2019). 
Percebe-se um total de 16 profissionais $(53,3 \%)$ com mais de sete anos de experiência na área. Em contraposição a isso, 23,3\%, o que equivale a sete bibliotecários, tem entre seis meses e um ano. Ainda assim, a maior parte deles demonstra - com as respostas - certa vivência na área. Correlacionando esta às três questões anteriores, pode-se afirmar que os respondentes da pesquisa são pessoas com faixa etária acima dos 30 anos, com uma média de sete a dez anos de formadas e com uma experiência na área que ultrapassa os sete anos.

Por fim, questionou-se os participantes sobre o tipo de unidade de informação em que atuam. O gráfico a seguir traz as respostas:

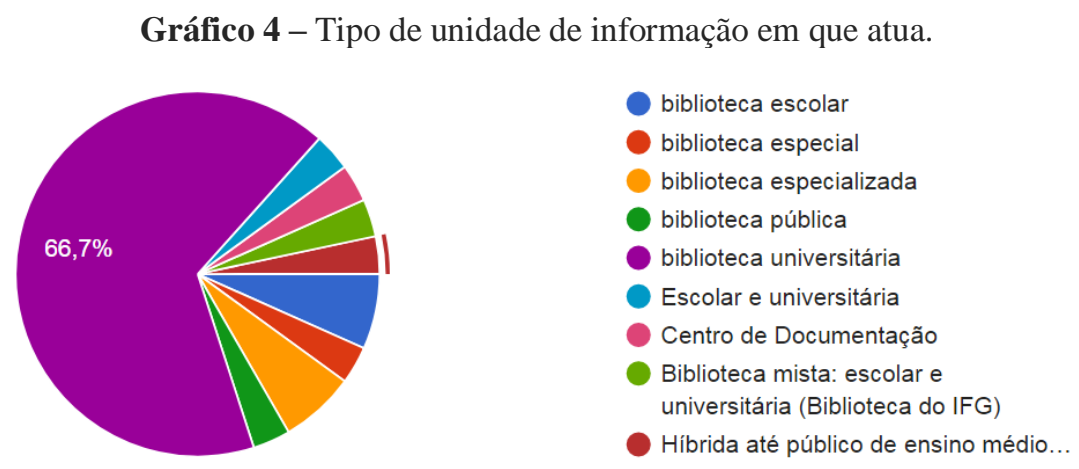

Fonte: elaborado pelos autores (2019).

Apesar de se tratarem, na grande maioria $(66,7 \%)$, de bibliotecários universitários, observa-se uma variedade enorme de unidades de informação, incluindo-se entre elas centros de documentação, bibliotecas tanto escolares quanto universitárias e até mesmo as consideradas híbridas, por englobarem tanto público do ensino médio quanto do ensino superior e da pós-graduação. Considera-se essa diversidade extremamente importante, porque permite um mapa representativo do tratamento temático via resumo nas bibliotecas goianas. Isso em razão da possibilidade de olhar simultaneamente para várias realidades diferentes, cada qual com suas particularidades no trato informacional, o que culmina em um diagnóstico abrangente.

O segundo bloco do questionário versou sobre o tratamento da informação desenvolvido na unidade. A princípio os bibliotecários foram indagados acerca dos processos técnicos que realizam na unidade em que atuam, no que se constatou que: 


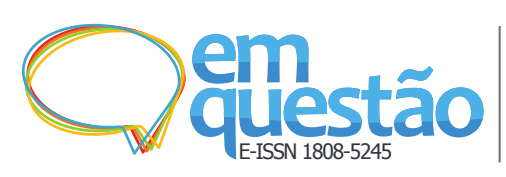

Gráfico 5 - Processos técnicos realizados pelo bibliotecário na unidade.

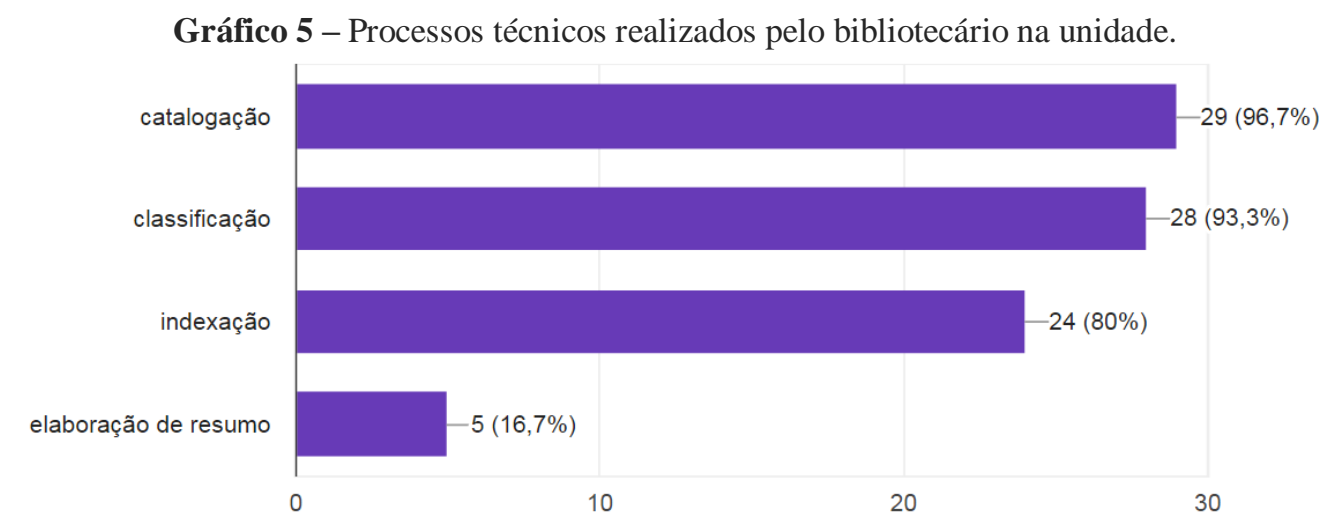

Fonte: elaborado pelos autores (2019).

Essa questão permitia assinalar mais de uma opção. Consegue-se, com isso, perceber quantos processos de tratamento informacional são realizados conjuntamente pelos bibliotecários. Como demonstra o gráfico acima e é de praxe, catalogação e classificação são os processos técnicos mais desenvolvidos - atingindo quase que o percentual total - sendo seguidos de perto pela indexação.

A elaboração de resumo, por sua vez, é realizada somente por cinco bibliotecários em um universo de 30. É interessante, nesse ponto, estabelecer um vínculo com o contexto no qual essa prática se estabelece. Trata-se de dois profissionais de biblioteca universitária, um de biblioteca escolar e universitária, um de biblioteca especializada e um de biblioteca escolar. Reflexo, portanto, de práticas sistematizadas em prol de um universo de ensino ou de funções organizacionais pontualmente delimitadas. E no que concerne ao tempo de atuação dos bibliotecários, três deles têm acima de sete anos, um tem entre quatro e seis anos e apenas um tem entre seis meses e um ano de atuação. São então, sujeitos experientes e com uma vivência significativa.

Ainda assim - e guardadas as devidas particularidades desse pequeno quantitativo - é uma diferença bastante significativa, já que em outras 25 unidades essa atividade de condensação não é feita, estando o tratamento temático amparado apenas pela constituição de notações (classificação) e de descritores (indexação). Tendo em vista que o resumo também facilita a identificação de itens do acervo (LANCASTER, 2004), esse tipo de restrição no emprego de tal instrumento desfavorece a busca e recuperação. 
Em continuidade, perguntados sobre qual processo é priorizado no tratamento temático da informação os profissionais responderam que:

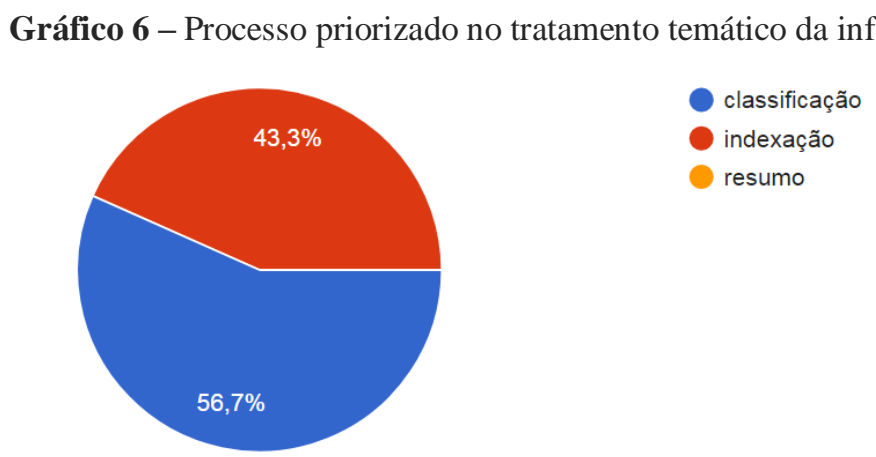

Fonte: elaborado pelos autores (2019).

Corrobora-se, assim, com o constatado na pergunta anterior. Os bibliotecários classificam $(56,7 \%)$ e indexam $(43,3 \%)$ os materiais do acervo, mas não incluem o resumo como um processo de tratamento temático da informação, já que não é feito um uso real do mesmo. Esse segundo bloco acaba, portanto, evidenciando um cuidado no tratamento descritivo via catalogação e no tratamento temático via classificação e indexação, somente.

Com tais constatações, pode-se afirmar que os bibliotecários goianos priorizam a sumarização da informação de que falam Fujita, Rubi e Boccato (2009) apenas via catalogação, classificação e indexação. O que representa uma perda real por ser o resumo justamente um elemento de síntese, que trata textos (KOBASHI, 1997). O ato de resumir seria, então, um complemento fundamental, em razão até da condensação diferenciada que proporciona, não em forma de atributo descritivo, de notação ou de palavra-chave, mas de texto direto e conciso sobre o original.

O terceiro e último bloco do questionário abordou especificamente a elaboração de resumos. A questão inicial buscou constatar se a indexação de assunto é sempre complementada pela elaboração de resumos. O gráfico abaixo expõe os percentuais: 


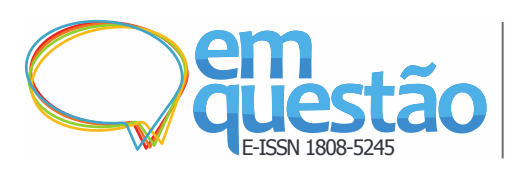

A elaboração de resumos documentários como atividade do tratamento temático da informação na prática profissional bibliotecária

Lais Pereira de Oliveira, Daniel Martínez-Ávila e José Augusto Chaves Guimarães

Gráfico 7 - Complemento da indexação de assunto pela elaboração de resumos.

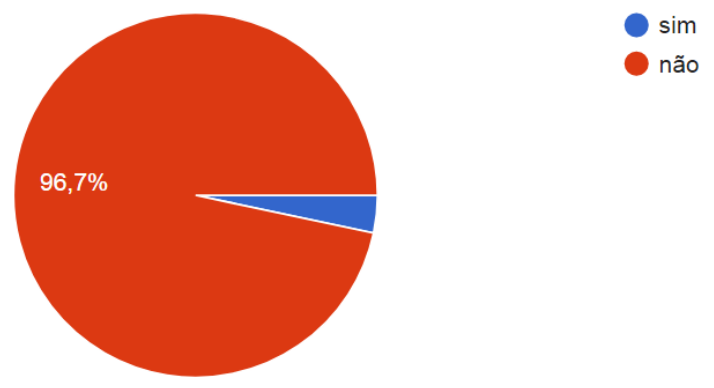

Fonte: elaborado pelos autores (2019).

Conforme demonstra o gráfico acima, em 29 bibliotecas $(96,7 \%)$ a indexação de assunto não é complementada pela elaboração de resumos. Apenas em uma isso acontece. Mais uma vez percebe-se um tratamento temático fragmentado que não se aproveita do resumo. Além disso, complementando os dados demonstrados no gráfico cinco - de que cinco unidades fazem resumo tem-se aqui um indicativo de que em quatro, resumir acontece independentemente do ato de indexar e, somente em uma, são ações conjuntas.

Esse resultado corrobora a percepção anteriormente destacada sobre a pequena exploração do potencial do resumo, assim como se alinha à constatação obtida nas duas perguntas do bloco dois do questionário. Perde-se com isso até mesmo a rica macrosseleção textual viabilizada pelo resumo (TERRA, 2017), que permitiria ao profissional se apoiar nele para constituir as demais operações de tratamento temático da informação.

A literatura é coerente ao evidenciar a proximidade entre indexação e resumos e a importância de que tais processos sejam conduzidos juntos (LANCASTER, 2004), garantindo com isso uma amplitude diferenciada no tratamento temático da informação. Ademais, a elaboração do resumo permite complementar a representação de assunto conseguida com a classificação e com a indexação (CAFÉ; SALES, 2010). Logo, é fundamental que o resumo seja enxergado pelos profissionais, passando também a ser considerado no trabalho técnico biblioteconômico.

A pergunta seguinte questionou se na unidade de informação o resumo é elaborado para todas, para algumas ou para nenhuma das obras do acervo. $\mathrm{O}$ gráfico a seguir apresenta os resultados: 
Gráfico 8 - Nível de elaboração do resumo.
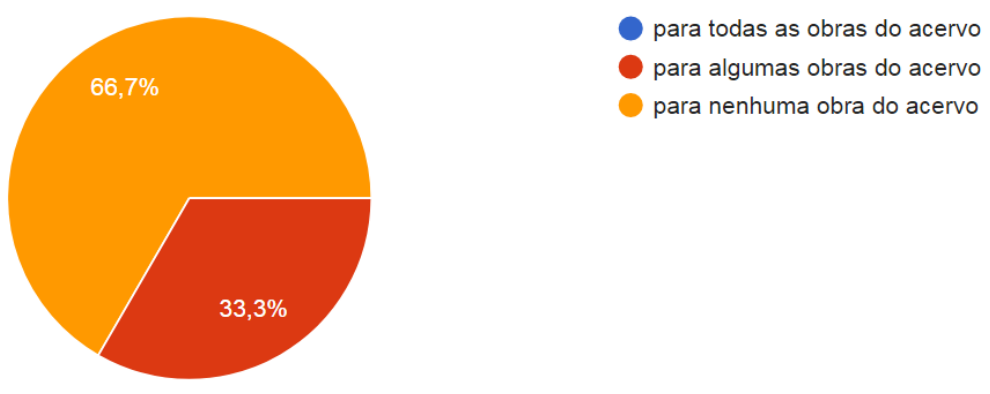

Fonte: elaborado pelos autores (2019).

Constata-se pelos percentuais acima que em 20 unidades $(66,7 \%)$ o resumo não é elaborado para nenhuma obra do acervo e, em dez (33,3\%), é feito apenas para algumas obras. Nenhum dos respondentes sinalizou haver a prática de constituir resumos para todo o acervo disponível, reforçando o dado precedente segundo o qual o resumo não é um complemento real à indexação.

Nota-se aqui uma falta de sistematização no tratamento temático via resumo, posto que em dado anterior - gráfico cinco - ficou demonstrado um quantitativo de apenas cinco locais a se dedicarem na elaboração de resumos. Contudo, outros cinco admitem, nessa pergunta, construir resumo para algumas obras. Nesse sentido, depreende-se que essa prática não é devidamente enxergada pelos bibliotecários como um dos processos técnicos que desenvolvem, na medida em que não é rotulada como tal.

Assim, os dados em questão acabam por indicar que o resumo não se estabelece como atividade complementar ao tratamento temático da informação no contexto investigado, o que seria de fato esperado. Logo, como terceiro processo de descrição de conteúdo da organização da informação (CAFÉ; SALES, 2010), resumir precisa se tornar uma prática cotidiana e se firmar como tal, em condições de inverter esses percentuais. Se não para todo o acervo, ao menos para parte dele. Inclusive porque se reconhece a dificuldade de condução dessa ação e as particularidades que envolvem sua realização.

$\mathrm{Na}$ intenção de ampliar a compreensão sobre o conjunto de profissionais que se dedica a construir resumos documentários, indagou-se aos bibliotecários 
se a unidade em que atuam costuma aproveitar o resumo que acompanha algumas obras para que não seja preciso elaborar um, no que se observou que:

Gráfico 9 - Aproveitamento do resumo que acompanha algumas obras.

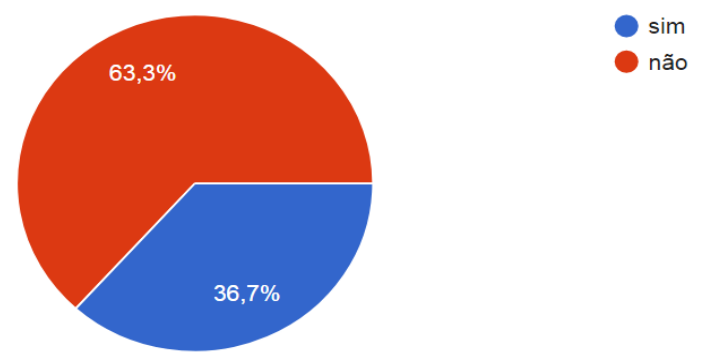

Fonte: elaborado pelos autores (2019).

Nota-se que em 19 unidades de informação (63,3\%) não há aproveitamento do resumo que acompanha algumas obras; em apenas 11 $(36,7 \%)$ isso acontece. Esse dado está relacionado com o expressivo quantitativo que não tem a prática de elaborar resumos, sinalizado na questão anterior. Desse modo, um elemento importante que poderia auxiliar na representação temática textual propiciada pelo resumo, que é a síntese contida na própria obra, acaba não tendo seu potencial aproveitado.

Impedimentos naturalmente existem, pelo fato de não haver resumos em todos os materiais e, também, por não serem exclusivamente acervos de natureza bibliográfica-textual os existentes nas bibliotecas. Mas ainda assim esse facilitador de aproveitamento do resumo das obras deveria ser utilizado nos casos em que fosse possível.

Considerando o número reduzido de bibliotecários e a carência de recursos que muitas bibliotecas enfrentam, no contexto investigado como também em outras realidades, seria essa uma via para que resumos documentários fossem constituídos, ainda que se amparando em uma estrutura prévia advinda do material analisado.

Mesmo porque o aproveitamento do resumo contido nas obras economizaria tempo. No máximo seria demandado algum acréscimo ou ajuste na estrutura, podendo o profissional se dedicar a outras atividades na sequência. Esse amparo também permitiria reduzir as dúvidas na ocasião da elaboração, sobre a própria seleção e hierarquização das informações (TERRA, 2017). 
Dando sequência à investigação, perguntados se consideram relevante elaborar resumos para complementar a indexação de assunto dos materiais, os bibliotecários disseram que:

Gráfico 10 - Relevância da elaboração de resumos para complementar a indexação de assunto.

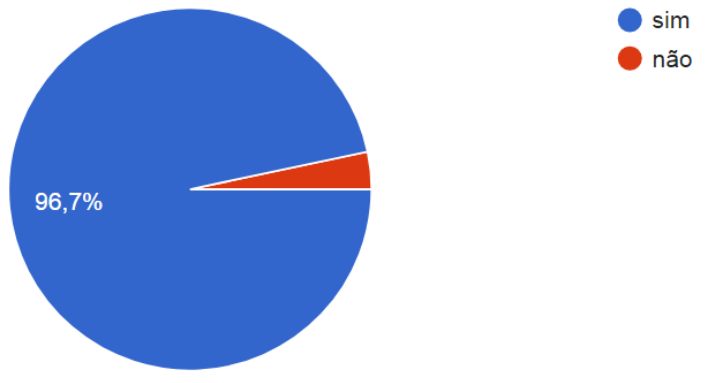

Fonte: elaborado pelos autores (2019).

Aqui se constata que, apesar de pouco explorado pelos bibliotecários goianos, o resumo é reconhecido em sua importância por 29 de um total de 30 respondentes. Os profissionais consideram que o resumo é relevante para complementar a indexação de assunto, sendo então um elemento a mais para garantir um tratamento temático mais completo dos materiais.

O contraditório é que, apesar de ser visto em seu potencial de apoio à indexação, para garantir uma representação temática completa dos materiais, na prática o resumo não é explorado como tal. Esse tipo de constatação demonstra a necessidade de novas investigações pautadas, contudo, pelos aspectos formativo e aplicado do tratamento temático da informação. Especialmente porque muito do que se estabelece na teoria influencia na atuação profissional e, os processos de trabalho em si, são diretamente regulados pelo que o aluno apreendeu ao longo da formação obtida na sua graduação.

Ademais, é importante ressaltar as características do único respondente que sinalizou a não relevância do resumo para complemento da indexação. Trata-se de profissional de biblioteca especial que tem entre um e três anos de experiência como bibliotecário e o mesmo tempo de formado. Tal posição pode estar relacionada ao universo de atuação, ao qual não associou ainda, essa necessidade de elaborar resumos. E mesmo, condizer com o breve período como graduado a desempenhar a função, de modo que ainda não tenha despertado para todos os aspectos relativos ao trato informacional. 
$\mathrm{Na}$ sequência os participantes foram questionados se se sentem confortáveis e capacitados para elaborar resumos representativos e que complementem a indexação de assunto que é realizada na unidade. O gráfico abaixo expõe os resultados:

Gráfico 11 - Nível de conforto e capacitação para elaborar resumos representativos.

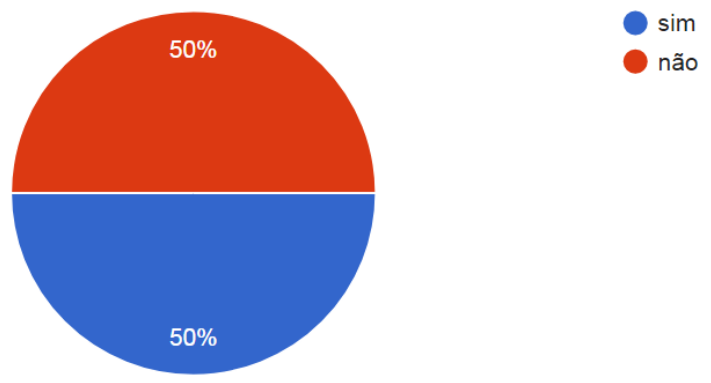

Fonte: elaborado pelos autores (2019).

Como indicam os percentuais, 15 bibliotecários (50\%) não se sentem confortáveis e em condições de elaborar resumos representativos capazes de complementar a indexação. A outra metade sinalizou que sim. Essa divisão reflete a prática que alguns profissionais já adquiriram por se dedicarem à elaboração de resumos documentários - ainda que seja apenas para parte do acervo - conforme resultado obtido e demonstrado no gráfico oito. De certo modo isso pode lhes dar mais segurança para desempenho desse processo técnico.

Entretanto, há que se destacar que no contexto dos 15 bibliotecários que não se sentem confortáveis e capacitados para elaborar resumos, nove deles têm mais de sete anos de experiência; um tem de quatro a seis; dois de um a três; e três, de seis meses a um ano. Um quantitativo expressivo destes, portanto, é experiente; ainda assim, não se considera apto para atuar como resumidor. Logo, demonstra-se que o tempo de profissão não é o único elemento capaz de dar confiança e condições a esses profissionais para desempenho dessa ação.

Nesse ponto também se reitera a necessidade de investigações que se dediquem mais à fundo ao aspecto formativo em tratamento temático da informação. Especialmente porque um número expressivo de bibliotecários - 12 - formados, já experientes, sinaliza aqui para a existência de dificuldades na realização de um processo técnico dessa dimensão em organização da 
informação. Tais pesquisas podem ajudar a compreender o cerne de tais impedimentos com relação ao resumo documentário.

Por fim, indagou-se os profissionais sobre os aspectos que consideram mais complicados na elaboração de resumos. O gráfico a seguir apresenta as respostas:

Gráfico 12 - Aspectos mais complicados na elaboração de resumos.

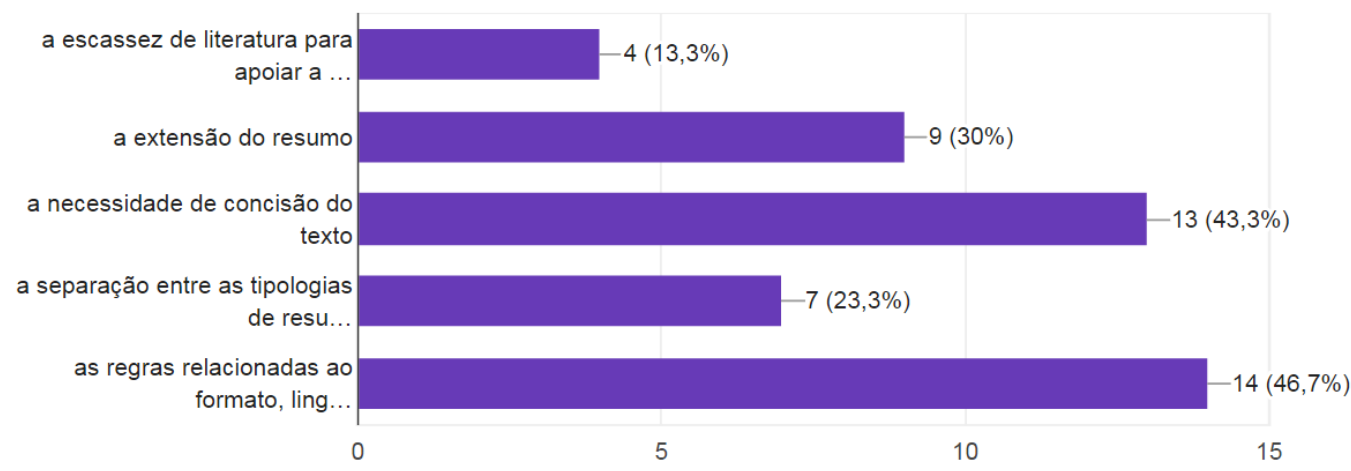

Fonte: elaborado pelos autores (2019).

A questão permitia marcar mais de uma opção, de forma que um mesmo respondente poderia sinalizar dificuldades múltiplas. Ainda assim, observa-se pelo gráfico acima que os bibliotecários consideram mais complicado entre todas as alternativas: as regras relacionadas ao formato, linguagem e extensão do texto, indicadas por 14 respondentes; seguidas pela necessidade de concisão do texto, apontada por 13 deles. Também foi expressivo o número de profissionais que sinalizaram dificuldades com a extensão do resumo e mesmo com a separação entre as tipologias de resumo indicativo, informativo e crítico, em um total de nove e sete, respectivamente.

Como se observa, há dificuldades estruturais que têm a ver com o processo de elaboração, o qual demanda capacidade de síntese para separar informação essencial da acessória (KOBASHI, 1997). Além do que envolve compreensão da normativa para redação de resumos. Apoio na norma garante regulação da atividade e diminuição das dúvidas envoltas na prática do resumidor. A própria política de indexação, documento formal norteador do tratamento temático, poderia ser uma via para dirimir esses empecilhos. 
Questões estruturais, contudo, podem não ser o único problema. A dificuldade na compreensão do texto base a ser resumido pode representar outro impedimento, que acabará por impactar nos aspectos estruturais de elaboração do resumo.

Apesar de assinalada por apenas quatro bibliotecários, a escassez de literatura para apoiar a elaboração também merece ser ressaltada. Esse tipo de integração entre teoria e prática, muito comentada em função da importância, precisa ser mais efetiva sobretudo em processos complexos como a estruturação de resumos documentários. Não se trata aqui apenas da precariedade de padrões de que fala Kobashi (1997), mas inclusive de estudos, de investigações científicas que tragam constatações teóricas e que permitam avançar na compreensão desse elemento tão importante que é o resumo.

\section{Conclusão}

A pesquisa se propôs a analisar em que medida o resumo documentário é elaborado durante o processamento técnico nas bibliotecas, como forma de apoiar a indexação para garantir uma representação temática completa dos materiais. O objetivo central foi alcançado.

Constatou-se, porém, que o resumo não é considerado no tratamento temático da informação desenvolvido nas unidades investigadas. Apesar de reconhecerem a sua importância para complementar a representação possibilitada pela indexação, os profissionais não elaboram resumos documentários. Consequentemente, o resumo não se estabelece como processo técnico adicional em vias de agregar ao processamento técnico cotidiano.

A hipótese de pesquisa se mostra, nesse sentido, verdadeira. $\mathrm{O}$ resumo, em detrimento de sua relevância, é pouco explorado pelos bibliotecários investigados - majoritariamente de bibliotecas universitárias. Empecilhos estruturais representam a maior parcela de dificuldades, incorrendo nessa pequena utilização do resumo. Mas outros fatores precisam ser investigados e enxergados na medida de sua influência sobre essa prática.

Como esperado, catalogação, classificação e indexação são processos técnicos cuidadosamente desenvolvidos e reconhecidos como parte do 
tratamento temático, aspecto que parece ser omitido para o caso dos resumos. Assim, um valioso nível de representação informacional se perde, uma vez que a sumarização textual não é prática cotidiana e sobre sua condução existem, inclusive, diversas dificuldades, como indicaram os pesquisados.

Ainda que as constatações da pesquisa não representem o ideal, sinalizam justamente para a necessidade de ampliar o potencial representativo nas bibliotecas via resumo. E nisso está sua importância. O processamento técnico tradicional, dedicado ao tratamento da informação a nível descritivo e temático em acervos físicos, que pode parecer superado e bem resolvido para quem lida com o universo digital, na verdade tem suas lacunas e as investigações é que demonstrarão isso.

Conforme sinalizado no decorrer da análise dos dados entende-se que as perspectivas conceitual, formativa e a aplicada do tratamento temático da informação precisam ser igualmente exploradas nas pesquisas da área de Biblioteconomia. Respostas relevantes e reconhecimento de eventuais demandas de aperfeiçoamento nos processos biblioteconômicos podem surgir daí. Com isso, as dimensões teórica, técnica e prática dos processos de catalogação, classificação, indexação e resumos, se alinham e se complementam.

Estudos futuros podem ser desenvolvidos a partir do outro viés do resumo, exposto na introdução, qual seja sua presença enquanto elemento da comunicação científica e mesmo, do resumo documentário como instrumento de tratamento da informação em outros contextos. Além disso, novas pesquisas podem expandir a perspectiva que aqui foi apresentada, para explorar o âmbito qualitativo e garantir outras constatações acerca desse importante produto do tratamento temático que é o resumo.

\section{Referências}

ASSOCIAÇÃO BRASILEIRA DE NORMAS TÉCNICAS. NBR 6028: informação e documentação: resumo: apresentação. Rio de Janeiro: ABNT, 2003.

CAFÉ, Lígia Maria Arruda; SALES, Rodrigo de. Organização da informação: conceitos básicos e breve fundamentação teórica. In: ROBREDO, Jaime; BRÄSCHER, Marisa (Orgs.). Passeios pelo bosque da informação: estudos 
sobre representação e organização da informação e do conhecimento. Brasília: IBICT, 2010. p. 115-129.

CINTRA, Anna Maria Marques et. al. Para entender as linguagens documentárias. São Paulo: Polis; APB, 1994.

FUJITA, Mariângela Spotti Lopes; RUBI, Milena Polsinelli; BOCCATO, Vera Regina Casari. As diferentes perspectivas teóricas e metodológica sobre indexação e catalogação de assuntos. In: FUJITA, Mariângela Spotti Lopes (Org.). A indexação de livros: a percepção de catalogadores e usuários de bibliotecas universitárias. Um estudo de observação do contexto sociocognitivo com protocolos verbais. São Paulo: Cultura Acadêmica, 2009. p. 19-42.

GUIMARÃES, José Augusto Chaves. O resumo como instrumento para a divulgação e a pesquisa científica. Revista Brasileira de Educação Especial, Marília, v. 11, n. 1, p. 3-16, jan./abr. 2005.

GUIMARÃES, José Augusto Chaves; SANTOS, João Carlos Gardini. A ementa jurisprudencial como resumo informativo em um domínio especializado: aspectos estruturais. Brazilian Journal of Information Studies: Research Trends, v. 10, n. 3, p. 32-43, 2016.

JIZBA, Laurel. Reflections on Summarizing and Abstracting: Implications for Internet Web Documents, and Standardized Library Cataloging Databases. Journal of Internet Cataloging, v. 1, n. 2, p. 15-39, 1997.

KOBASHI, Nair Yumiko. Resumos documentários: uma proposta metodológica. Revista de Biblioteconomia de Brasília, v. 21, n. 2, p. 201-210, jul./dez. 1997.

LANCASTER, F. W. Indexação e resumos: teoria e prática. 2. ed. rev. atual. Brasília: Briquet de Lemos, 2004.

LUNARDELLI, Rosane Suely Alvares. Mecanismos de distanciamento linguístico: a preservação da face na síntese documental. Perspectivas em Ciência da Informação, v. 22, n. 1, p. 4-16, jan./mar. 2017.

LUZ, Ana Cristina de Oliveira. Critérios para a elaboração de resumos. Revista de Biblioteconomia de Brasília, v. 20, n. 1, p. 27-40, 1996.

OLIVEIRA, Lais Pereira de. Análise das publicações na área de organização e tratamento da informação à luz dos resumos. Revista ACB: Biblioteconomia em Santa Catarina, Florianópolis, v. 23, n. 2, p. 245-266, abr./jul. 2018.

SIMÕES, Maria da Graça Melo. Resumo documental e literatura científica: origem, desenvolvimento e consolidação. Páginas a\&b, s. 3, n. 3, p. 15-36, 2015. 
TERRA, Ana Lúcia. Processos cognitivos na leitura documental: o que faz o indexador quando lê? In: FUJITA, Mariângela Spotti Lopes; NEVES, Dulce Amélia de Brito; DAL'EVEDOVE, Paula Regina (Orgs.). Leitura documentária: estudos avançados para a indexação. Marília: Oficina Universitária; São Paulo: Cultura Acadêmica, 2017. p. 51-67.

\title{
Summarization as an activity of subject representation in librarian professional practice
}

\begin{abstract}
Considering the summary as an element of the subject representation of information, it aims to analyze to what extent the document summaries are created during the technical processing of materials in libraries, as a way to support the indexation and guarantee a complete subject representation of the materials. This paper make use of data collection through questionnaire with closed questions, applied by Google Forms to 30 librarians active in different types of information units in Goiás. A statistical systematization is carried out. The results show that the processes of summarization and abstracting are not common practices by the librarians, to the detriment classification and indexing. The summary is created only in $16,7 \%$ of the information units, but seen in its importance by $96,7 \%$ respondents. There are several difficulties in conducting these activities as indicated by the respondents. We concluded that document summaries and abstracts, in spite of the professional's recognition of their importance, are not effectively being used in libraries as part of the subject representation of information activities.
\end{abstract}

Keywords: Subject representation. Document summaries and abstracts. Summarization.

Recebido: 27/02/2019

Aceito: $29 / 06 / 2019$

\footnotetext{
${ }^{1}$ Pesquisa aprovada pelo Comitê de Ética em Pesquisa/CEP-UFG, sob o parecer n ${ }^{\circ} 1.986 .331$.
} 